\title{
Living high training low induces physiological cardiac hypertrophy accompanied by down-regulation and redistribution of the renin-angiotensin system
}

\author{
Wei SHI ${ }^{1,2, *}$, J Gary MESZAROS ${ }^{3}$, Shao-ju ZENG ${ }^{1}$, Ying-yu SUN ${ }^{1}$, Ming-xue ZUO ${ }^{1, *}$ \\ ${ }^{1}$ Laboratory of Neuroscience and Brain Development, School of Life Science, Beijing Normal University, Beijing 100875, China; ${ }^{2}$ School \\ of Biomedical Sciences, Kent State University, Kent, OH 44240, USA; ${ }^{3}$ Department of Integrative Medical Sciences, Northeastern Ohio \\ Universities Colleges of Medicine and Pharmacy, Rootstown, $\mathrm{OH} 44272$, USA
}

Aim: Living high training low" (LHTL) is an exercise-training protocol that refers living in hypoxia stress and training at normal level of $\mathrm{O}_{2}$. In this study, we investigated whether LHTL caused physiological heart hypertrophy accompanied by changes of biomarkers in reninangiotensin system in rats.

Methods: Adult male SD rats were randomly assigned into 4 groups, and trained on living low-sedentary (LLS, control), living lowtraining low (LLTL), living high-sedentary (LHS) and living high-training low (LHTL) protocols, respectively, for 4 weeks. Hematological parameters, hemodynamic measurement, heart hypertrophy and plasma angiotensin II (Ang II) level of the rats were measured. The gene and protein expression of angiotensin-converting enzyme (ACE), angiotensinogen (AGT) and angiotensin II receptor I (AT ${ }_{1}$ ) in heart tissue was assessed using RT-PCR and immunohistochemistry, respectively.

Results: LLTL, LHS and LHTL significantly improved cardiac function, increased hemoglobin concentration and RBC. At the molecular level, LLTL, LHS and LHTL significantly decreased the expression of ACE, AGT and AT 1 genes, but increased the expression of ACE and $\mathrm{AT}_{1}$ proteins in heart tissue. Moreover, $\mathrm{ACE}$ and $\mathrm{AT}_{1}$ protein expression was significantly increased in the endocardium, but unchanged in the epicardium.

Conclusion: LHTL training protocol suppresses ACE, AGT and AT1 gene expression in heart tissue, but increases ACE and AT 1 protein expression specifically in the endocardium, suggesting that the physiological heart hypertrophy induced by LHTL is regulated by regionspecific expression of renin-angiotensin system components.

Keywords: exercise-training; living high training low; hypoxia stress; heart hypertrophy; renin-angiotensin system; angiotensin-converting enzyme; angiotensin II receptor; cardiac function

Acta Pharmacologica Sinica (2013) 34: 342-351; doi: 10.1038/aps.2012.210; published online 4 Feb 2013

\section{Introduction}

Exercise training, like swimming and running, improves several aspects of human physical aerobic performance ${ }^{[1]}$. The most common exercise-training protocol has involved "living high and training low" (LHTL), and this has been adopted using low-oxygen gas mixtures to simulate altitude exposure with training at normal oxygen level ${ }^{[2]}$. The LHTL training protocol has been shown to enhance aerobic metabolism ${ }^{[1-3]}$. The adaptation of LHTL protocol may precondition the heart, induce cardiac hypertrophy and improve cardiac contractility $^{[3,4]}$. Although it is well known that exercise train-

\footnotetext{
* To whom correspondence should be addressed.

E-mail mxzuo@bnu.edu.cn (Ming-xue ZUO); shiweiphd@gmail.com (Wei SHI)

Received 2012-07-05 Accepted 2012-11-28
}

ing can improve cardiac function ${ }^{[5]}$, the mechanisms responsible for this positive adaptation to exercise training remain obscure. Exercise training and pathological events can cause different types of cardiac hypertrophy and have contrasting effects on cardiac function ${ }^{[6]}$. An unresolved question in cardiac biology is whether different mechanisms are responsible for the development of pathological and physiological cardiac hypertrophies in the adult heart. Physiological hypertrophy is characterized by a normal organization of cardiac structure and enhanced cardiac function ${ }^{[7]}$, whereas pathological hypertrophy is associated with an altered pattern of cardiac gene expression, fibrosis, cardiac dysfunction, and increased morbidity and mortality ${ }^{[6]}$. However, few studies have investigated the effects of exercise training on physiological cardiac hypertrophy.

The molecular adaptation that we have addressed in our 
study involves the renin-angiotensin system (RAS) gene and protein expression. The renin-angiotensin cascade begins when renin cleaves angiotensinogen to generate angiotensin I, and the vasopressor octapeptide angiotensin II is derived primarily from the action of membrane-bound or circulating angiotensin-converting enzyme $(\mathrm{ACE})^{[8]}$. ACE, also known as kininase II, catalyzes the deactivation of vasodilator bradykinin (BK). In addition to endocrine RAS, RAS are now welldescribed in many tissues such as the myocardium ${ }^{[9]}$, skeletal muscle $^{[10]}$ and adipose tissue ${ }^{[11]}$. RAS play a variety of roles in regulating tissue growth, recovering from injury and metabolic responses.

A polymorphism of the $\mathrm{ACE}$ gene was described in which the absence (deletion or ' $\mathrm{D}$ ' allele) rather than the presence (insertion or ' $\mathrm{I}$ ' allele) of a 287-base-pair marker in intron 16 was associated with significantly higher ACE levels in circulation $^{[12]}$, as well as in tissue systems, including the human myocardium ${ }^{[13,14]}$. Previous studies have suggested that the I-allele was associated with fatigue-resistance ${ }^{[15]}$ and elite endurance performance ${ }^{[16]}$, especially in hypoxic environments ${ }^{[15]}$. Meanwhile, ACE and its product Ang II play an important role in ventricular remodeling and improvement of cardiac function ${ }^{[17]}$. Given these findings, we predict that the changes in ACE expression may be adaptations responsible for the improved cardiac function resulting from the LHTL training protocol.

\section{Materials and methods}

\section{Experimental animals, training protocol and tissue collection}

Sixty adult male Sprague-Dawley (SD) rats (6 weeks old, weight $200 \mathrm{~g}$ ) with similar genetic backgrounds were used in our study.

The animals were bred and raised under pathogen-free conditions and a controlled ambient temperature of $20^{\circ} \mathrm{C}$, with $60 \%-80 \%$ relative humidity and a $12 \mathrm{~h}$ light $/ 12 \mathrm{~h}$ dark cycle, in the laboratory animal services center of Beijing Normal University. All animal procedures were approved by Animal Investigational Committee of Beijing Normal University (Permit № SYXK2009-0010) under the control of Beijing Municipal Science \& Technology Commission and performed in accordance with the guide for the Care and Use of Laboratory Animals published by the Beijing Municipal People's Congress standing committee.

All other rats were pre-trained for one week with the protocol of $20 \mathrm{~m} / \mathrm{min}$ for $30 \mathrm{~min} / \mathrm{d}$ and $5 \mathrm{~d} /$ week, and 40 animals with better physical performance were chosen for our living high-training low protocol. These rats were then randomly divided into four groups, each of which had 10 rats: group A, the control (living low-sedentary, or LLS); group B, living lowtraining low (LLTL); group C, living high-sedentary (LHS); group D, living high-training low (LHTL). Living high-training low refers to living in a hypoxic environment while training in an environment of normal oxygen concentration. In the living high-sedentary and in living high-training low groups, SD rats were placed in a hypoxic chamber and exposed to inspired oxygen at $15 \%$ (equivalent to an altitude of $3000 \mathrm{~m}$ ) every night for $12 \mathrm{~h}$. In the exercise-training group, SD rats ran on the animal treadmill at the speed of $25 \mathrm{~m} / \mathrm{min}$ (represent $60 \%$ of $V_{\mathrm{O} 2}$ ) for $1 \mathrm{~h} / \mathrm{d}$ and $5 \mathrm{~d} /$ week for four consecutive weeks, the details of LHTL training protocol were described before $^{[2,18,19]}$.

After four weeks of training, the animals were anesthetized by injecting 0.1 to $0.3 \mathrm{~mL}$ pentobarbital sodium depending on the body weight $(30 \mathrm{mg} / \mathrm{kg})$ and their blood pressure was measured as described below. After that, the animals were perfused with $0.9 \%$ sodium chloride. The hearts were then isolated and weighed immediately after the perfusion, following by quickly snap-freezing the heart in liquid nitrogen.

\section{Hematological parameters, hemodynamic measurement, and} cardiac hypertrophy

Blood samples were taken at 8:00 am on the Monday before training, as well as the second week and fourth weeks posttraining. Blood samples were drawn from the tail into EDTAcoated tubes. Whole blood was assayed in duplicate for hemoglobin concentration by spectrophotometer (GBC, Cintra 10e). Red blood count (RBC) ${ }^{[20]}$ was determined with an blood cell arithmometer (ABX Micros 60, France) and blood glucose (kit from Nanjing Jiancheng Inc, Nanjing, China) was determined by the spectrophotometer (GBC, Cintra 10e $)^{[21]}$.

End systolic pressure was measured in anesthetized animals by carotid catheterization. Catheters attached to Statham $\mathrm{P} 23 \mathrm{Db}$ pressure transducers were implanted into the abdominal aorta through the left femoral artery (PP-10 in PP-50, Portex Corp, Hythe, UK) and the signal was recorded by a Maclab 400 (AD Instruments, Castle Hill, Australia). After several minutes of stable recordings, the catheters were advanced through the aorta and into the left ventricle to measure the blood pressure in the left ventricle. The details of this method were described before ${ }^{[11,22,23]}$.

The atria were removed and the ventricles were blotted dry and weighed to determine indices of ventricular hypertrophy. Ventricular hypertrophy was calculated by the heart weight/ body weight ratio ${ }^{[24]}$.

\section{Determination of plasma concentrations of Ang II}

Plasma and cardiac Ang II concentration were assessed by a standard technique with a commercial radioimmunoassay kit (North Biotechnology Research Inc, China). Venous blood samples were drawn at 8:00 am in the Monday before training, as well as the Monday of second week and the fourth week. Animals are sacrificed and heart tissue samples were collected on the fourth week.

\section{Real-time quantitative PCR}

We isolated total RNA from 20 rat hearts ( $n=5$ for each experimental and control group, because the gene expression and immunochemistry studies require different animals; five rats were randomly chosen for each study from the 10 rats in each group) using the TRIzol reagent (supplied by Shenggong Company, Shanghai, China). Total RNA was digested by RNase-free DNase (TAKARA, Dalian, China) to remove any 
genomic DNA. Total RNA $(0.5 \mu \mathrm{g})$ was used for first-strand cDNA synthesis with Oligo-dT primers and M-MLV reverse transcriptase (MBI, Fermentas, USA) in a final volume of 20 $\mu \mathrm{L}$. After incubation at $42^{\circ} \mathrm{C}$ for $1 \mathrm{~h}$, the cDNA product was diluted 10 times and a $2.5 \mu \mathrm{L}$ aliquot was used for PCR amplification (TOYOBO, Japan). The primer sequences employed in the current study were:

$\beta$-actin sense: GTGGGCCGCCCTAGGCACCA;

antisense: CGGTTGGCCTTAGGGTTCA.

ACE sense: TCGTGGAGGAGTATGACCG;

antisense: ATCCGCTTGATGGTAGAGTT.

AGT sense: ACAGCATCCTCCTTGAACTCC;

antisense: CCTGAGTCCCGCTCGTAGAT.

$\mathrm{AT}_{1} \mathrm{R}$ sense: GATGGGAGGTCAAGAGTTT;

antisense: AAGACATTATTCAGGCAAG.

The real-time PCR conditions for all four genes (ACE, AGT, $\mathrm{AT}_{1} \mathrm{R}, \beta$-actin) were as follows: 40 cycles of denaturing at $94^{\circ} \mathrm{C}$ for $30 \mathrm{~s}$; annealing at $59^{\circ} \mathrm{C}$ for $15 \mathrm{~s}$; and elongation at $72^{\circ} \mathrm{C}$ for $45 \mathrm{~s}$. The results were analyzed with the ABI $7900 \mathrm{HT}$ sequence Detection System (Applied Biosystems Inc, Forster City, CA, USA). We used the delta-delta CT to determine the amount of gene expression, using $\beta$-actin as a housekeeping gene.

\section{Immunohistoschemistry}

We randomly chose five rat hearts from each group out of 10 totally and immediately immerse them in $4 \%$ paraformaldehyde (PFA, $\mathrm{pH}$ 7.4). The distribution of $\mathrm{ACE}$ and $\mathrm{AT}_{1}$ antigen in the right and left ventricles was assessed after LHTL training protocol by immunohistochemistry using a monoclonal $\mathrm{ACE}$ and $\mathrm{AT}_{1}$ antibody (Santa Cruz Biotechnology Inc, Santa Cruz, CA, USA). Cryostat sections of frozen tissue were cut 10 $\mu \mathrm{m}$ thick and fixed in ethanol for $10 \mathrm{~min}$ at room temperature. $\mathrm{ACE}$ and $\mathrm{AT}_{1}$ antigens were detected by biotinylated goat antirabbit IgG (Vector Biotechnologies LLC) at 1:1000 and then followed by an avidinbiotin-peroxidase complex (Vector Biotechnologies LLC) at 1:150. Color development was achieved by incubating with 3,3'-diaminobenzidine 4-HCl (DAB, Sigma).

Serial sections of hearts from control and experimental rats were processed together and stained with a range of primary antibody dilutions to allow comparison of signals between groups. Thus, $\mathrm{ACE}$ and $\mathrm{AT}_{1}$ expression in any vessel could be defined in terms of the dilution of antibody at which the signal could still just be detected. For analysis, transverse sections of rat heart were stained with anti-ACE antibody or anti-AT antibody as described above using a fixed antibody concentration of $0.5 \mathrm{mg} / \mathrm{mL}$. After counterstaining, the sections were viewed under a $20 \times$ objective and all $\mathrm{ACE}$ or $\mathrm{AT}_{1}$-positive cells visible in 10 randomly selected fields were counted. Their number was expressed as $\mathrm{ACE}$ or $\mathrm{AT}_{1}$-positive cells.

\section{Statistical analysis}

Results were expressed as the mean \pm SEM. mRNA expression was expressed as the ratio of the target gene normalized to $\beta$-actin expression. Measurement of blood glucose and hemoglobin were analyzed by two-way ANOVA and Student $t$-test. The hematological changes, hemodynamic studies, and the expression of $\mathrm{ACE}, \mathrm{AGT}$, and $\mathrm{AT}_{1}$ genes and proteins were analyzed by one-way ANOVA followed by multiple comparisons using Fisher's protected least-significant difference test. A $P$-value of $<0.05$ was considered statistically significant.

\section{Results \\ Body weight, hematological parameters, blood pressure and cardiac hypertrophy are improved by LHTL protocol}

To determine the baseline condition of each subject, we measured body weight (Table 1) and blood glucose. There was a significant increase in the blood glucose levels of the LHTL group after two weeks of training compared to the LHTL group before training $(6.59 \pm 1.11 \mathrm{mmol} / \mathrm{L}$ vs $4.9 \pm 1.15 \mathrm{mmol} / \mathrm{L}$, $n=10, P<0.05)$. The LLTL and LHS groups showed a significant decrease in blood glucose levels after four weeks of training compared to the same group before training $(3.60 \pm 0.50$ $\mathrm{mmol} / \mathrm{L}$ vs $5.73 \pm 0.86 \mathrm{mmol} / \mathrm{L}, 3.96 \pm 0.45 \mathrm{mmol} / \mathrm{L}$ vs $4.90 \pm 1.15$ $\mathrm{mmol} / \mathrm{L}, n=10, P<0.05$, Figure $1 \mathrm{~A})$.

Table 1. Body weight changes in the four groups. (A) Living low-sedentary group (LLS or control group); (B) Living low -training low group (LLTL); (C) Living high-sedentary group (LHS); (D) Living high-training low group (LHTL). Body weight was measured before any treatment (PRE) and during the second weeks (2nd) and in the fourth weeks (4th). Data are expressed as means \pm SEM. $n=10$ (analyzed by one way ANOVA). ${ }^{c} P<0.01$ vs PRE.

\begin{tabular}{cccc}
\hline $\begin{array}{c}\text { Body } \\
\text { weight (g) }\end{array}$ & PRE & 2nd week & 4th week \\
\hline A & $209.0 \pm 40.0$ & $252.1 \pm 38.1$ & $264.2 \pm 35.5$ \\
B & $216.7 \pm 35.7$ & $269.3 \pm 18.3$ & $293.9 \pm 20.9^{\circ}$ \\
C & $222.8 \pm 21.8$ & $288.2 \pm 28.2$ & $298.5 \pm 35.5^{\circ}$ \\
D & $192.8 \pm 37.9$ & $247.4 \pm 56.4$ & $269.0 \pm 46.0^{\circ}$ \\
\hline
\end{tabular}

To determine the effect of the exercise training protocol on hematologic changes, we initially measured hemoglobin and red blood counts. Hemoglobin mass in the LHS group significantly increased after two weeks of training compared to the LLS group $(158.77 \pm 10.38 \mathrm{~g} / \mathrm{L}$ vs $125.84 \pm 15.71 \mathrm{~g} / \mathrm{L}$, $n=10, P<0.05$, Figure 1B). Hemoglobin mass in the LLTL and LHTL groups significantly increased after four weeks of training compared to the LLS group (LLTL: $188.45 \pm 20.57 \mathrm{~g} / \mathrm{L}$ vs $133.75 \pm 10.37 \mathrm{~g} / \mathrm{L}$; LHTL: $172.15 \pm 15.53 \mathrm{~g} / \mathrm{L}$ vs $133.75 \pm 10.37$ $\mathrm{g} / \mathrm{L}, n=10, P<0.05$, Figure 1B). Hemoglobin in the LLTL and LHS groups significantly increased after four weeks of training compared to the same groups before training (LLTL: $188.45 \pm 20.57 \mathrm{~g} / \mathrm{L}$ vs $138.77 \pm 18.57 \mathrm{~g} / \mathrm{L}$; LHS: $176.15 \pm 21.81 \mathrm{~g} / \mathrm{L}$ vs $123.37 \pm 9.84 \mathrm{~g} / \mathrm{L}, n=10, P<0.05$, Figure $1 \mathrm{~B})$.

The red blood cell counts in the LLTL, LHS, and LHTL groups increased significantly after four weeks of training compared to the LLS group (LLTL: $269.58 \pm 102.40$ vs 195.70 \pm 50.38 ; LHS: $359.80 \pm 165.74$ vs $195.70 \pm 50.38$; LHTL: $297.09 \pm 143.53$ vs $195.70 \pm 50.38, n=10, P<0.05$, Table 2$)$, but there were no significant differences after two weeks of train- 
A1
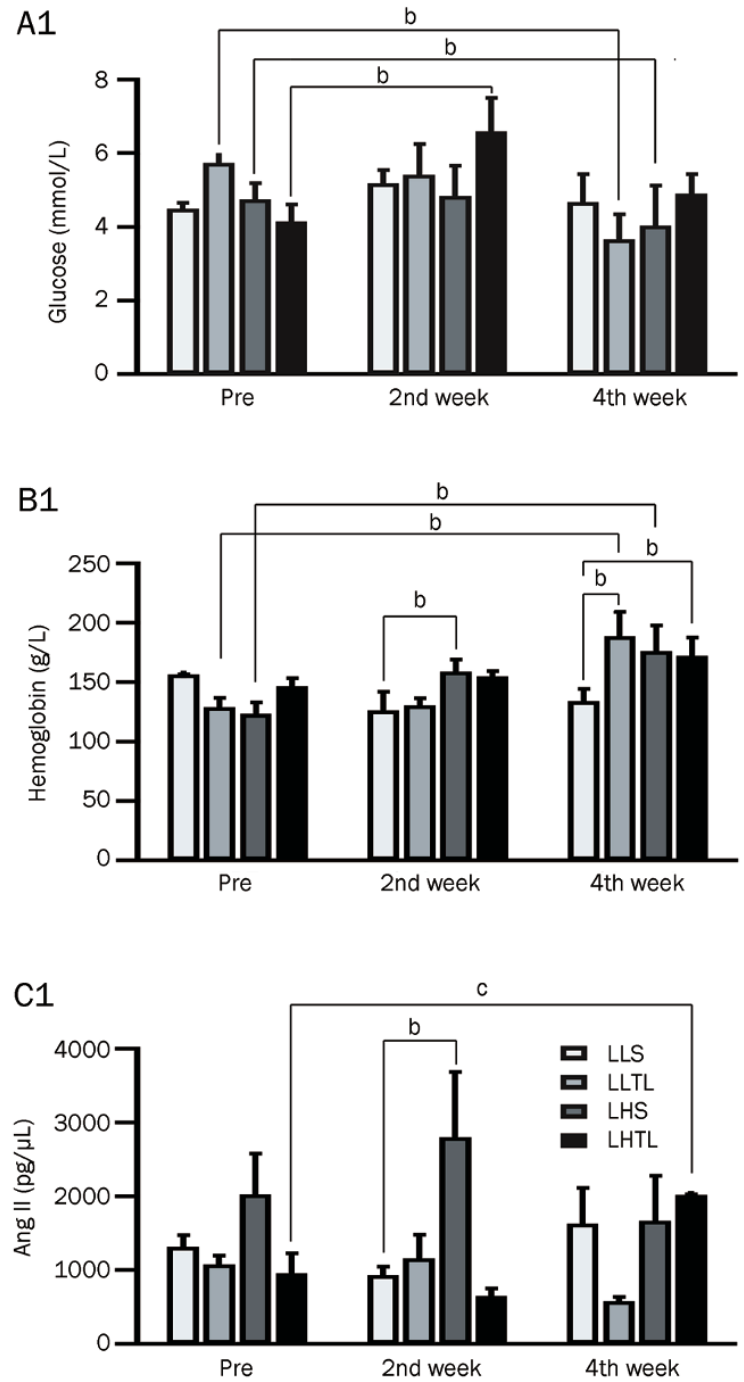

A2

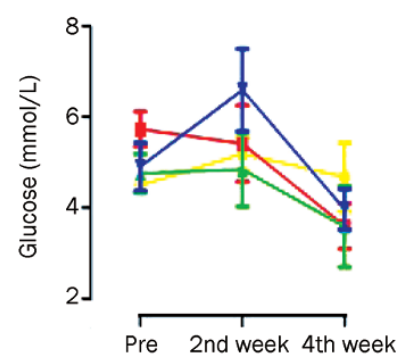

B2

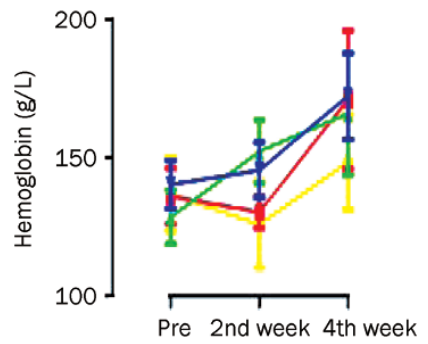

C2

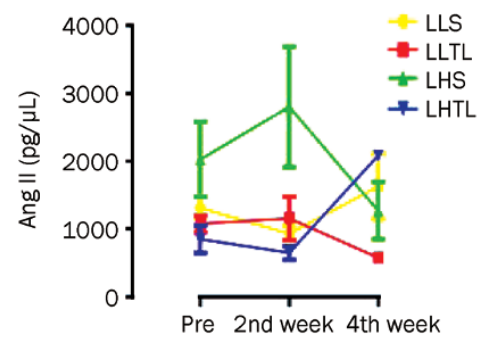

Figure 1. Blood glucose (A1), hemoglobin (B1), and angiotension II (C1) concentration before the training protocol (pre), during the second week (2nd week) and in the fourth week (4th week) for living low-sedentary (LLS) group, living low-training low (LLTL) group, living high-sedentary (LHS) group, living high-training low (LHTL) group. ${ }^{b} P<0.05,{ }^{c} P<0.01$ (analyzed by Student $t$-test). We found significant interaction effects of various training time and protocol in the blood glucose, hemoglobin concentration and Ang II concentration by two-way ANOVA.

ing. These data suggest that our training protocol can induce a time-dependent increase in the hemoglobin mass and red

Table 2. Red blood count (RBC) changes before any treatment (PRE), during the second weeks (2nd week) and in the fourth weeks (4th week). (A) Living low-sedentary (LLS) group; (B) Living low-training low (LLTL) group; (C) Living high-sedentary (LHS) group; (D) Living high-training low (LHTL) group. Data are expressed as means \pm SEM. ${ }^{\circ} P<0.01$ vs $A$ in 4 th week. $n=10$ (analyzed by one-way ANOVA).

\begin{tabular}{cccc}
\hline RBC/L & PRE & 2nd week & 4th week \\
\hline A & $522.00 \pm 301.46$ & $232.38 \pm 25.79$ & $195.70 \pm 50.38$ \\
B & $757.38 \pm 359.96$ & $548.90 \pm 332.78$ & $269.58 \pm 102.40^{\circ}$ \\
C & $775.88 \pm 429.16$ & $425.60 \pm 429.76$ & $359.80 \pm 165.74^{\circ}$ \\
D & $744.75 \pm 289.67$ & $217.67 \pm 14.75$ & $297.09 \pm 143.53^{\circ}$
\end{tabular}

blood count.

Next, we observed a significant increase of Ang II in the LHS group compared to the LLS group after second week of training $(2800.63 \pm 884.17 \mathrm{pg} / \mu \mathrm{L}$ vs $932.86 \pm 116.01 \mathrm{pg} / \mu \mathrm{L}$, $n=10, P<0.05$, Figure 1C). Meanwhile, there was a significant increase of Ang II in the LHTL group after fourth week of exercise training compared to before training $(2085.44 \pm 65.99$ $\mathrm{pg} / \mu \mathrm{L}$ vs $850.70 \pm 199.17 \mathrm{pg} / \mu \mathrm{L}, n=10, P<0.05$, Figure $1 \mathrm{C})$. This result is related with the ACE protein expression, which will be described below.

To determine the effect of exercise training on cardiac function, hemodynamic changes and blood pressure were measured as an indicator of cardiac contractility. We observed a significant increase in left ventricle systolic pressure (LVSP) of the LLTL, LHS and LHTL groups compared to the LLS group (LLS: $95.55 \pm 29.59 \mathrm{mmHg}$; LLTL: $135.87 \pm 11.67 \mathrm{mmHg}$; 
LHS: $154.15 \pm 9.03 \mathrm{mmHg}$; LHTL: $141.82 \pm 23.06 \mathrm{mmHg}, n=10$, $P<0.01$, Figure 2D), and we observed a significant increase in left ventricle diastolic pressure (LVDP) of the LHS and LHTL groups compared to the LLS group (LLS: $18.79 \pm 2.53$ $\mathrm{mmHg}$; LHS: $35.44 \pm 5.28 \mathrm{mmHg}$; LHTL: $36.28 \pm 3.77 \mathrm{mmHg}$, $n=10, P<0.01$, Figure $2 \mathrm{C}$ ). There was a significant increase of $\mathrm{mSP}$ in the LHTL groups compared to the LLS group (LLS: $125.58 \pm 15.88 \mathrm{mmHg}$; LHTL: $165.07 \pm 9.85 \mathrm{mmHg}$, $n=10, \quad P<0.05$, Figure 2E). There was a significant increase of $\mathrm{d} p / \mathrm{d} t_{\max }$ in the LHS and LHTL groups compared to the LLS group (LLS: $2766.96 \pm 899.90 \mathrm{mmHg} / \mathrm{s}$; LHS: $4875.26 \pm 914.68$ $\mathrm{mmHg} / \mathrm{s}$; LHTL: $3414.97 \pm 705.74 \mathrm{mmHg} / \mathrm{s}, n=10, P<0.05$, Figure $2 \mathrm{~B})$. All of the above results indicate an improvement of cardiac contractility by the LHTL protocol (Figure 2).

The heart/body weight was higher in the LLTL, LHS, and LHTL groups compared to the LLS control group (LLS: $3.6 \pm 0.21 \mathrm{mg} / \mathrm{kg}$; LLTL: $4.6 \pm 0.25 \mathrm{mg} / \mathrm{kg}$; LHS: $4.4 \pm 0.29 \mathrm{mg} / \mathrm{kg}$; LHTL: $4.7 \pm 0.41 \mathrm{mg} / \mathrm{kg}, n=10, P<0.05$, Figure $2 \mathrm{~A}$ ), suggesting a positive adaptation of physiological hypertrophy (Figure 2A). We compared the endocardium and epicardium of normal and exercised hearts histologically, observing the myocardial tissue in LLS control animals to be disorganized and scattered while the tissue in the LHTL hearts was observed to be continuous and well-organized (Figure 3A, 3B). Meanwhile, the epicardium was thicker in the control hearts as compared to the exercised hearts (Figure 3C, 3D) and the endocardium was thicker with enlarged left ventricles, indicating a hypertrophic adaptation to the LHTL exercise protocol (Figure 3E, 3F).

Decreases of the ACE, AGT, and $\mathrm{AT}_{1} \mathrm{R}$ mRNA levels in the LLTL, LHS, and LHTL group

We observed a marked effect of hypoxia and exercise training on the expression of RAS mRNA in rat hearts after four weeks of training in the LLTL, LHS, and LHTL groups. The expres- sion levels of ACE significantly decreased in the LLTL, LHS, and LHTL group compared to the LLS control group $(P<0.05$, $P<0.01, n=5$, Figure 4A). The expression levels of AGT in the LLTL, LHS, and LHTL groups significantly decreased compared to the LLS control group, with the LHTL group showing the most significant reduction $(P<0.05, P<0.01, n=5$, Figure 4). The expression of $A_{1} R$ mRNA significantly decreased in the LLTL, LHS, and LHTL group compared to the LLS control group $(P<0.05, P<0.01, n=5$, Figure $4 \mathrm{C})$.

Increased protein expression of ACE and $\mathrm{AT}_{1}$ in the LLTL, LHS, and LHTL group

We next examined by immunohistochemistry the relative protein expression levels of $A C E$ and $A_{1} R$ in the epicardium and endocardium. There were no significant difference in ACE and $\mathrm{AT}_{1}$ protein expression levels in the epicardium $(P>0.05$, $n=5)$ and significantly increased $\mathrm{ACE}$ and $\mathrm{AT}_{1}$ protein expression in the endocardium of the LLTL, LHS, and LHTL groups compared to the LLS group $(P<0.01, n=5$, Figure 5,6$)$. The total protein expression levels of ACE in the LHS, and LHTL groups significantly increased over the LLS group $(P<0.05$, $n=5)$, with the largest increase occurring in the LHTL group (Figure 5E). The total protein expression levels of $\mathrm{AT}_{1}$ in the LHTL group significantly increased over the LLS group $(P<0.05, n=5$, Figure 6E).

\section{Discussion}

We utilized an LHTL exercise protocol to assess the involvement of the RAS in physiological hypertrophy and cardiac function. In order to determine the effects of hypoxia and exercise training on these parameters, we initially measured several parameters related to cardiovascular function including hemodynamic parameters, heart/body weight ratio and hematological changes. Our exercise training protocol was
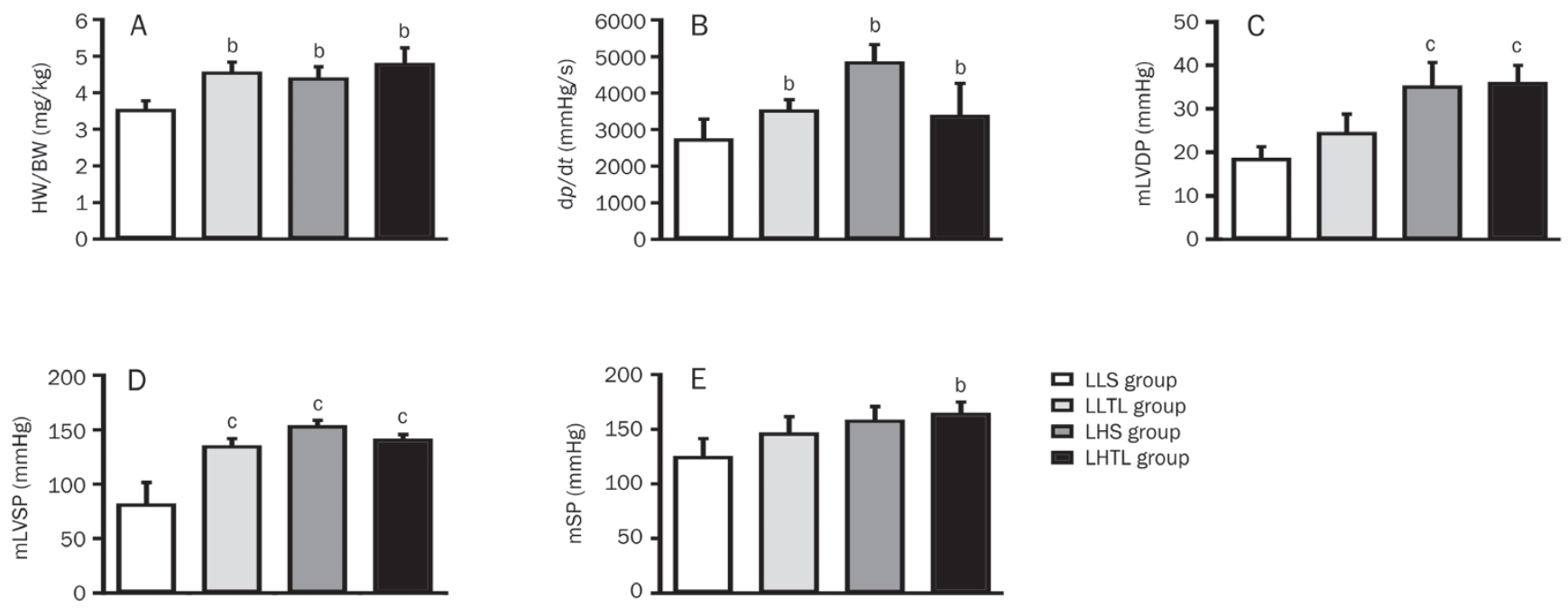

Figure 2. Heart weight/body weight $(A), d p / d t_{\max }(B)$, left ventricle diastolic pressure $m L V D P(C)$, left ventricle systolic pressure $m L V S P(D)$, and systolic pressure $\mathrm{mSP}(\mathrm{E})$ measurements in the living low-training low group (LLTL), living high-sedentary group (LHS), living high training-low group (LHTL) compared with living low-sedentary control group (LHS). ${ }^{b} P<0.05,{ }^{c} P<0.01$ vs LLS group. $n=10$ (analyzed by one-way ANOVA). 

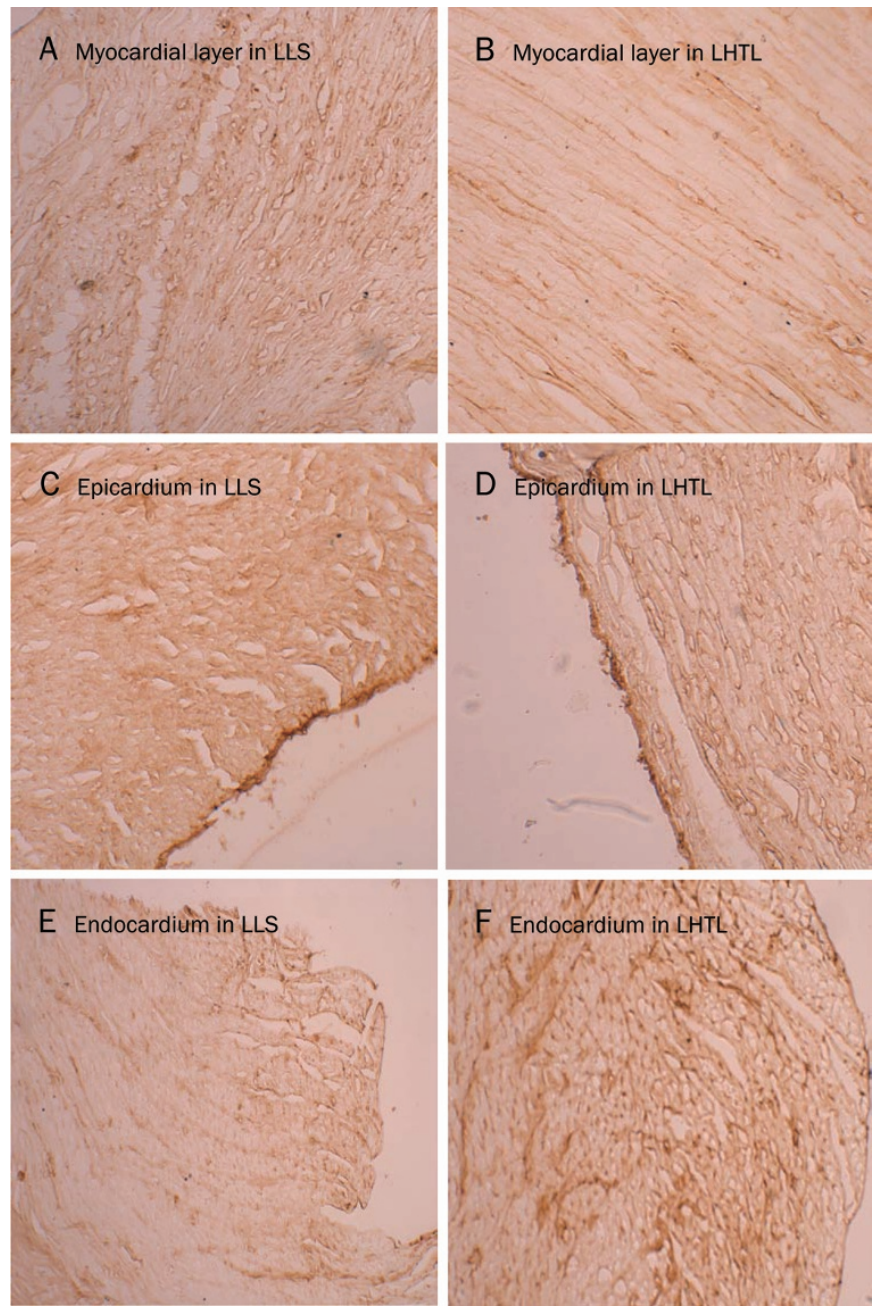

Figure 3. Photomicrographs of myocardial layer in living low-sedentary (LLS) group and living high-training low (LHTL) group. (A and B) show the myocardial layer in the LLS heart array scattered and whereas the myocardial layer in the LHTL heart array appears well organized. ( $C$ and D) shows that the epicardium is thicker in LLS heart compared to the LHTL heart. ( $E$ and $F$ ) shows that the endocardium is thinner in the LLS heart compared to the LHTL heart.

long enough to induce cardiac hypertrophy ${ }^{[25]}$. In general, exercise training can improve vascular compliance ${ }^{[11]}$ and improve myocardial contractility. The increase of $\mathrm{d} p / \mathrm{d} t_{\max }$ in the LHTL group indicated that LHTL protocol can improve myocardial contractility. The mLVSP, mLVDP and $\mathrm{d} p / \mathrm{d} t_{\max }$ in both LH groups significantly increased compared to the LLS group, but the LHS group increased much more than the LHTL group. These data suggested that LHTL training protocol mostly improved cardiac contractility without the negative effects caused by hypoxia that will excessively raise the blood pressure $^{[23]}$. In addition, the improvement of cardiac function in the LLTL group was limited because only the mLVSP measurement was significantly increased compared to that of the LLS group.

It has been shown that in addition to the RAS, an intrinsic RAS existed in several diverse tissues, which may have clinical
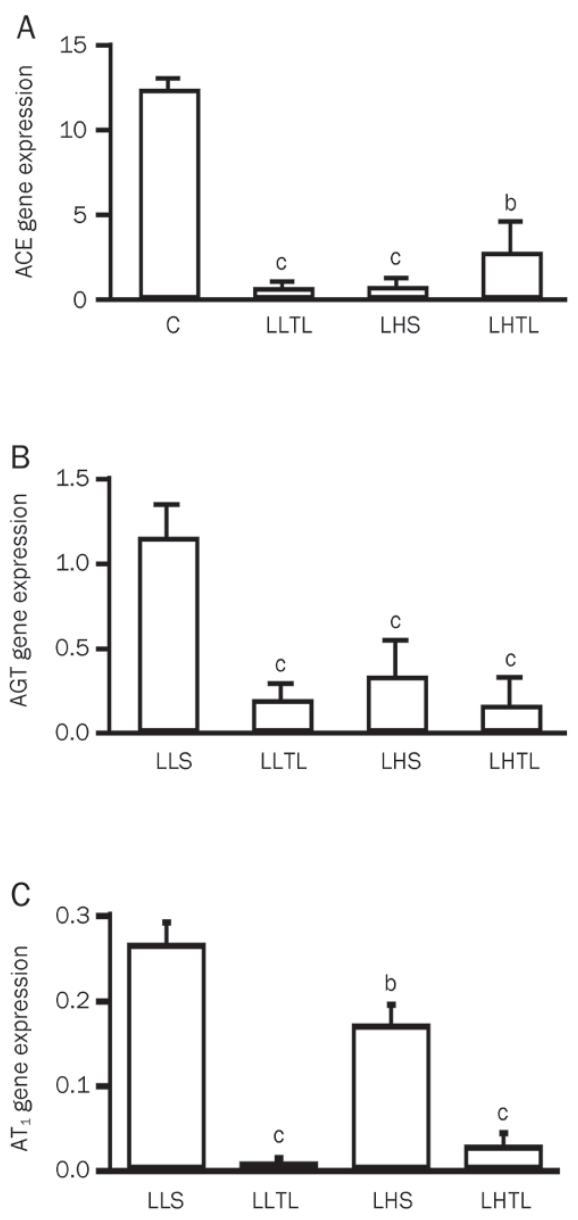

Figure 4. Gene expression of $A C E(A), A G T(B)$, and $A T_{1}(C)$ in the following four groups: living low-sedentary (LLS) group; living low-training low (LLTL) group; living high-sedentary (LHS) group; living high-training low (LHTL) group. Data were expressed as Mean \pm SEM. ${ }^{\mathrm{b}} P<0.05,{ }^{\mathrm{c}} P<0.01$ vs LLS group. $n=5$ (analyzed by one-way ANOVA).

implications ${ }^{[26]}$. In the current study, we have presented evidence of the myocardial RAS and demonstrated that the ACE mRNA levels of all experimental groups (LLTL, LHS, and LHTL) decreased significantly when compared to the LLS control group. This decrease in the mRNA levels, however, was not related to the actual protein levels of the RAS protein molecules. This was likely to be due to the different time course of gene activation versus protein expression. The mRNAs for these molecules tend to increase early in the training and are transient ${ }^{[27]}$; by the time we assayed the tissues (after four weeks' training), the mRNA levels had declined to protect against the negative effects of ACE overexpression ${ }^{[28-31]}$. Thus, these data indicated that the LHTL training protocol markedly decreased ACE gene expression which some studies have suggested that down-regulation of ACE gene expression was beneficial for long-term exercise training ${ }^{[15]}$. Similar to ACE expression, the gene expression of $\mathrm{AGT}$ and $\mathrm{AT}_{1}$ was decreased in the three experimental groups (LLTL, LHS, and LHTL). We speculated that ACE played an important role in the feedback mechanism behind the adaptation to the LHTL 

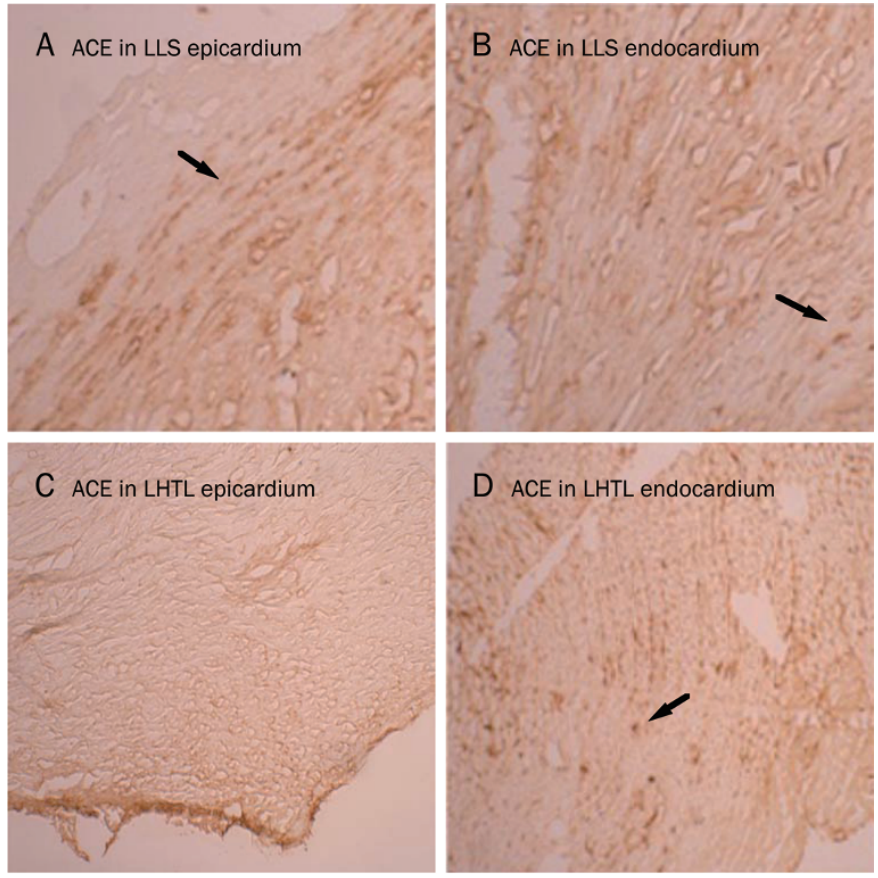

$E$

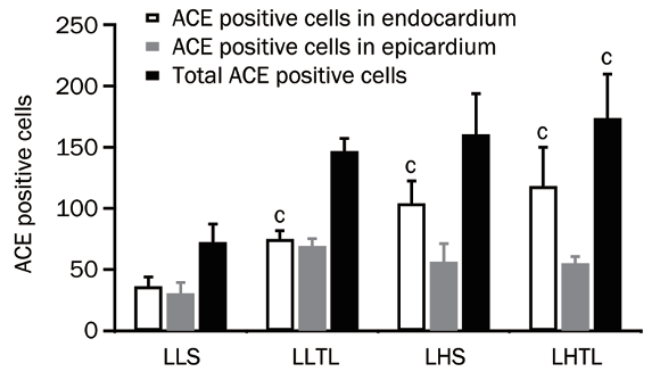

Figure 5. Photomicrographs of left ventricles in living low-sedentary group (LHS; A, B) and living low-training low (LHTL) rats (C, D) stained with anti-ACE monoclonal antibody. In the normal rat, ACE expression (dark yellow) was similar in the epicardium (A) and endocardium (B). After four weeks of LHTL training, ventricular ACE expression was observed in the endocardium (D) with less expression in the epicardium (C). Dark arrow shows the ACE-positive cell. (E) Distribution of ACE expression in the different exercise training groups: living low-sedentary (LLS) group; living low-training low (LLTL) group; LHS group; living high-training low group (LHTL). There is a significant increase of ACE expression in the endocardium in the LHS and LHTL group compared to the LLS group. There is a significant increase of ACE expression in the endocardium of the LLTL group compared to the LLS group (gray; $P<0.01, n=5$ ). The total ACE expression is significantly increased in the LHTL group and LHS group compared to the LLS group. Data were expressed as means \pm SEM. $n=5$ for each group. ${ }^{b} P<0.05,{ }^{c} P<0.01$ vs LLS gropup (analyzed by one-way ANOVA).

training condition and we further speculated AGT and $\mathrm{AT}_{1}$ can be regulated by ACE. Other studies have suggested that increased ACE gene expression during short-term training could induce angiogenesis ${ }^{[27]}$. In addition, the over-expression of ACE can cause adaptive hypertrophy of the cardiac muscle, resulting in reduced cardiac contractility and various patholo-
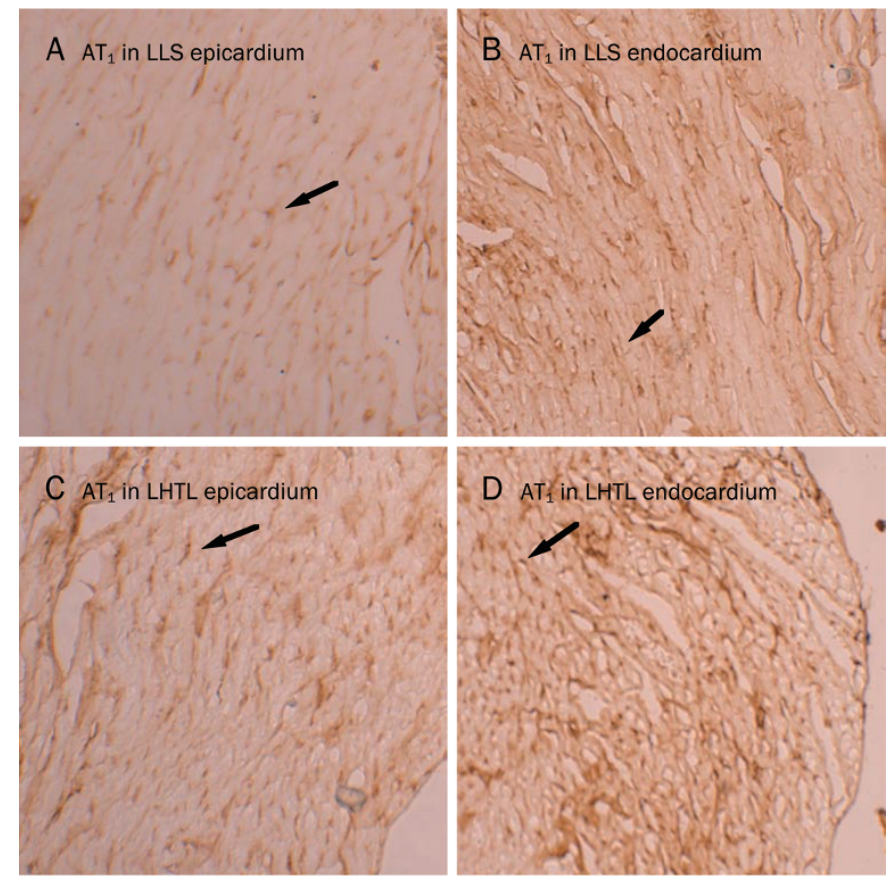

$E$

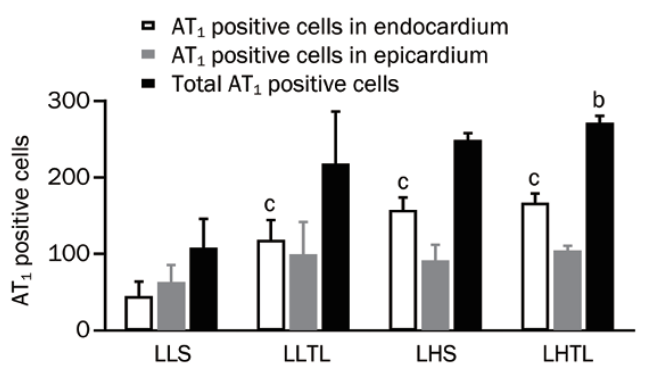

Figure 6. Photomicrographs of ventricle in the living low sedentary (A, B) and Hilo protocol rats $(\mathrm{C}, \mathrm{D})$ stained with anti-AT ${ }_{1}$ monoclonal antibody. In the living low-sedentary (LLS) rat, $\mathrm{AT}_{1}$ expression (dark yellow) was the same in the epicardium (A) and endocardium (B). After four weeks of living high-training low (LHTL) training protocol, ventricular $\mathrm{AT}_{1}$ expression observed in the endocardium (D) was higher than that in the epicardium (C). Dark arrow shows the ACE-positive cell. (E) The distribution of $\mathrm{AT}_{1}$ expression in LLS group, living low-training low (LLTL) group; living highsedentary (LHS) group, and LHTL group. There is a significant increase of $\mathrm{AT}_{1}$ expression in the endocardium of the LHTL and LHS group compared to the LLS group (white; $P<0.01 . n=5$ ). The total $\mathrm{AT}_{1}$ expression was significantly increased in the LHTL group after four weeks of LHTL protocol compared to the LLS group (black; $P<0.05 . n=5$ ). $n=5$ for each group. ${ }^{\mathrm{b}} P<0.05,{ }^{\mathrm{c}} P<0.01$ (analyzed by one-way ANOVA).

gies that can be reversed through the administration of ACE inhibitors $^{[32]}$. Therefore, we speculated that up-regulation of ACE gene expression through short-term training could enhance the process of angiogenesis. Moreover, down-regulation of ACE gene expression after four-weeks of training would provide additional protection from further pathologic changes.

The most novel aspect of the study was the data pertaining to the localization of RAS proteins within the epi- and 
endocardium. Normally, RAS was expressed in the myocardial capillaries, fibroblasts and vascular smooth muscle cells to influence proliferation, cardiac function and ventricular remodeling ${ }^{[17]}$. In LHTL hearts, our results indicated a significant redistribution of changes in RAS protein expression. Protein expression level of $\mathrm{ACE}$ and $\mathrm{AT}_{1}$ were lower in the epicardium compared to the endocardium, consisting of the myocardial capillaries and cardiomyocytes, which may be important in enhancing contractile performance. The heart/body weight and the photomicrographs demonstrated physiological hypertrophy observed after the training protocol. The endocardial and the myocardial layers in the LHTL group were thicker than those in the LLS controls, and these layers are essential for the improvement of cardiac contractility. We conclude that this unique distribution of $\mathrm{ACE}$ and $\mathrm{AT}_{1}$ in the endocardium may be what helps drive the physiological hypertrophy by stimulating the hypertrophic growth of the cardiomyocytes. Thus, the LHTL training protocol promoted redistribution of $\mathrm{ACE}$ and $\mathrm{AT}_{1}$, leading to compensatory hypertrophy in the endocardium that was capable of enhancing overall cardiac function.

Previous studies suggested that ACE inhibitors were effective pharmacological agents for treating diseases such as hypertension and diabetes ${ }^{[33-39]}$. Moreover, it has been established that ACE inhibitors can reduce blood pressure ${ }^{[40]}$. The current study, along with several others in the literature ${ }^{[41-46]}$, provided support for the notion that it would be advantageous to utilize exercise training instead of medicine to improve the function of the cardiovascular system. As our experiments suggested, the LHTL protocol could significantly decrease the ACE gene expression. Further research should address that these training protocols are viable supplemental treatments for hypertension. Although the possibility of exercisetraining therapy for hypertension had been raised by some previous studies ${ }^{[41,42]}$, it has some difficulties to implement the exercise-training therapy, such as regulating training intensity and moderating the possible negative impact induced by exercise training. The LHTL protocol can reduce the intensity of exercise that is necessary for regulating blood pressure beneficially. Additionally, maintaining $15 \%$ oxygen can improve several aspects of cardiovascular function and the oxygencarrying capacity of hemoglobin ${ }^{[18]}$. Certainly further research is necessary to validate the possible beneficial effects of the LHTL training protocol for regulating hypertension. Lastly, positive effects of ACE inhibitors for treating diabetes have also been suggested, as it was shown that these drugs could enhance the transport of the glucose $\mathrm{e}^{[47,48]}$. Our blood glucose results in the LLTL and LHTL groups indicated lower glucose levels than those in the sedentary group, demonstrating that the LLTL and LHTL protocol can effectively reduce the blood glucose levels and may have therapeutic implications for the maintenance of blood glucose levels in diabetes.

\section{Conclusion}

The current study suggested that the LHTL protocol can improve cardiac function, increase hemoglobin concentration and increase RBC. At the molecular level, LHTL training protocol significantly reduced gene expression of ACE, AGT, and $\mathrm{AT}_{1}$, which are beneficial for the long-term adaptation of the exercise training. Compared to the LLS animals, LHTL protocol induced a higher level of $\mathrm{ACE}$ and $\mathrm{AT}_{1}$ protein expression to the endocardium and increased cardiac ACE activity. Cardiac RAS gene regulation by LHTL protocol may be important for cardiopulmonary adaptation to chronic hypoxic stress during exercise training. Since high levels of ACE gene expression contributed to the early chronic elevation of blood pressure in human hypertension, LHTL protocol may be effective in treating this condition. Further work is required to explain the mechanisms behind gene regulation under the LHTL training protocol and to further define the relationship between ACE and cardiopulmonary adaptation to hypoxia with exercise training.

\section{Abbreviations}

LHTL, living high and training low; ACE, angiotensin-converting enzyme; AGT, angiotensinogen; Ang II, angiotensin II; $\mathrm{AT}_{1}$, Angiotensin II type 1 receptor.

\section{Acknowledgements}

This work was supported by grants from the National Natural Science Foundation of China (№ 30870307) and the Beijing Natural Science Foundation of China (No 5092013) to Mingxue ZUO. Also, the first author's parents and the China Education Department supported part of this work as an undergraduate student research fellowship. The authors gratefully thank Prof Xiao-li LIU, Associate Prof Qiu-yun LIU, William HAMLET and Dr Yong LU for the technical assistance and helpful review of the manuscript.

\section{Author contribution}

Wei SHI and Ming-xue ZUO designed the research; Wei SHI and Ying-yu SUN performed the experiments; Wei SHI analyzed data; Wei SHI, Shao-ju ZENG, and J Gary MESZAROS assisted with data interpretation and manuscript writing.

\section{References}

1 Wibler RL. Current trend in altitude training. Sports Med 2001, 31: 249-65.

2 Levine BD, Stray-Gundersen J. “Living high-training low" effect of moderate-altitude acclimatization with low-altitude training on performance. J Appl Physiol 1997, 83: 102-12.

3 Radzievsky PA, Shpak T, Polyshtchuk NV, Bakanichev AP. The changes of functional state and working capacity of Kayak-paddlers after interval hypoxic training with traditional sports training as a background. Hypoxia Med J 1993; 1: 30-3.

4 Koshelev VB, Tarasova OS, Storozhevykh TP, Baranov VS, Pinells VG, Rodionov IM. Changes in the systemic hemodynamics and the vascular bed of the skeletal muscles in rats adapted to hypoxia. Fiziol Zh SSSR Im IM Sechenova 1991; 77: 123.

5 Jin H, Yang R, Li W, Lu H, Ryan AM, et al. Effects of exercise training on cardiac function, gene expression, and apoptosis in rats. Am J Physiol Heart Circ Physiol 2000; 279: H2994-3002.

6 Lemitsu M, Miyauchi T, Maeda S, Sakai S, Kobayashi T, Fujii N, et al. 
Physiological and pathological cardiac hypertrophy induce different molecular phenotypes in the rat. Am J Physiol Regul Integr Comp Physiol 2001; 281: R2029-36.

7 Woodiwiss AJ, Norton G. Exercise-induced cardiac hypertrophy is associated with an increased myocardial compliance. J Appl Physiol 1995; 78: 1303-11.

8 Beldent V, Michaud A, Wei L, Chauvet MT, Corvol P. Proteolytic release of human angiotensin-converting enzyme: localization of the cleavage site. J Biol Chem 1993; 268: 26428-34.

9 Dzau VJ. Circulating versus local renin-angiotensin system in cardiovascular homeostasis. Circulation 1988; 77: I1-3.

10 Dragovic T, Minhall R, Jackman HL, Wang LX, Erdos EG. Kininase II-type enzymes: their putative rle in muscle energy meabolism. Diabetes 1996; 45: S34-7.

11 Jonsson JR, Game PA, Head RJ, Frewin DB. The expression and localization of the angiotensin-converting enzyme mRNA in human adipose tissue. Blood Pressure 1994; 3: 72-5.

12 Rigat B, Hubert C, Alhenc-Gelas F. An insertion/deletion polymorphism in the angiotensinogen and angiotensin-converting enzyme gene accounting for half the variance of serum enzyme levels. J Clin Invest 1990; 86: 1343-6.

13 Costerousse O, Allegrini J, Lopez M, Alhenc-Gelas F. Angiotensin I-converting enzyme in human circulating mononuclear cells: genetic polymorphism of expression in T-lymphocytes. Biochem J 1993; 290 : 33-40.

14 Danser AHJ, Schalekamp ADH, Bax WA, van den Brink AM, Saxena PR, Riegger GA, et al. Angiotensin-converting enzyme in the human heart: Effect of the deletion/insertion polymorphism. Circulation 1995; 92 : 1387-8.

15 Montgomery HE, Marshall R, Hemingway H, Myerson S, Clarkson P, Dollery C, et al. Human gene for physical performance. Nature 1998; 393: 221-2.

16 Myerson S, Hemingway H, Budget R, Martin J, Humphries S, Montgomery $\mathrm{H}$, et al. Human angiotensin I-converting enzyme gene and endurance performance. J Appl Physiol 1999; 87: 1313-6.

17 Blaufarb IS, Sonnenblick EH. The renin-angitensin system in left ventricular remodeling. Am J Cardiol 1996; 77: 53.

18 Stray-Gundersen J, Robert F Chapman, Levine BD. “Living hightraining low" altitude training improves sea level performance in male and female elite runners. J Appl Physiol 2001; 91: 1113-20.

19 Shi W, Zhao Z, Pan JL, Yang XM. Effect of living high-training low and high glucose high fat diet on the renin-angiotensin system (RAS) gene expression in rat heart. J Guangzhou Phys Edu Inst 2010; 30: 86-90.

20 Wang T, Fu F, Zhang L, Han B, Zhu M, Zhang X. Effects of escin on acute inflammation and the immune system in mice. Pharmacol Rep 2009; 61: 697-704.

21 Marks V. An improved glucose-oxidase method for determining blood CSF and urine glucose levels. Clin Chim Acta 1959; 4: 395-400.

22 Recchia FA, McConnell PI, Bernstein RD, Vogel TR, Xu X, Hintze TH. Reduced nitric oxide production and altered myocardial metabolism during the decompensation of pacing-Induced heart failure in the conscious dog. Circ Res 1998, 83: 969-79.

23 Fletcher EC, Lesske J, Qian W, Miller CC, Unger T. Repetitive, episodic hypoxia causes diurnal elevation of blood pressure in rats. Hypertension 1992; 19: 555-61.

24 Byne JA, Grieve DJ, Bendall JK, Li JM, Gove C, Lambeth JD, et al. Contrasting roles of NADPH oxidase isoforms in pressure-overload versus angiotensin II-induced cardiac hypertrophy. Circ Res 2003; 93 : 802-5.

25 Miyazaki S, Sakai A. The effect of "living high-training low" on physical performance in rats. Int J Biometeorol 2000; 44: 24-30.
26 Leung PS. Intrinsic angiotensin-generating system: its tissue specific functions and clinical implications. Panminerva Med 2002; 44: 93-7.

27 Amaral SL, Papanek PE, Greene AS. Angiotensin II and VEGF are involved in angiogenesis induced by short-term exercise training. Am J Physiol Heart Circ Physiol 2001; 281: H1163-9.

28 Passier RC, Smits JFM, Verluyten MJS, Studer R, Drexler R, Daemen MJ. Activation of angiotensin converting enzyme exppression in infarct zone following myocardial infarction. Am J Physiol 1995; 269: H1268-76.

29 Pieruzzi F, Abassi ZA, Keiser HR. Expression of renin-angiotensin system components in the heart, kidneys, and longs of rats with experimental heart failure. Circulation 1995; 92: 3105-12.

30 Schunkert H, Dzau VJ, Tang SS, Hirsch AT, Apstein CS, Lorell BH. Increased rat cardiac angiotensin converting enzyme activity and mRNA expression in pressure overload left ventricular hypertrophy: effects on coronary resistance, contractility, and relaxation. J Clin Invest 1990; 86: 1913-20.

31 Yamada H, Fabris B, Allen AM, Jackson B, Johnston CL, Mendelsohn FAO. Localization of angiotensin converting enzyme in rat heart. Circ Res 1991, 681: 141-9.

32 Daemen MJ, Lombardi DM, Bosman FT, Schwartz SM. Angiotensin II induces smooth muscle cell proliferation in the normal and injured rat arterial wall. Circulation Research 1991; 68: 438-49.

33 Chappel MC, Ferrario CM. ACE and ACE2: their role to balance the expression of angiotensin II and angiotensin-(1-7). Kidney Int 2006, 70: 8-10.

34 Jacobsen P, Andersen S, Rossing K, Hansen BV, Parving HH. Dual blockade of the renin-angiotensin system in type I patients with diabetic nephropathy. Nephrol Dial Transplant 2002; 17: 1019-24.

35 Lewis EJ, Hunsicker LG, Bain BP, Rohde RD. The effect of angiotensinconverting enzyme inhibition on diabetic nephropathy. New Engl J Med 1993; 329: 1456-62.

36 Adbi R, Dong VM, Lee JC, Ntoso KA. Angiotensin II receptor blockerassociated angioedema on the heels of ACE inhibitor angioedema. Pharmacotherapy 2002; 22: 1173-5.

37 Doulton TWR, He FJ, Graham A, MacGregor GA. Systematic review of combined angiotensin-converting enzyme inhibition and angiotensin receptor blockade in hypertension. Hypertension 2005; 45: 880-6.

38 Nakao N, Yoshimura A, Morita HM, Takada T, Kayano T, Ideura T. Combination treatment of angiotensin II receptor blocker and angiotensin-converting enzyme inhibitor in non-diabetic renal disease (COOPERATE): a randomised controlled trial. The Lancet 2003; 361: 117-24.

39 McFarlane SI, Kumar A, Sowers JR. Mechanisms by which angiotensin-converting enzyme inhibitors prevent diabetes and cardiovascular disease. Am J Cardiol 2003; 91: 30-7.

40 Mogensen CE, Neldam S, Tikkanen I, Oren S, Viskoper R, Watts RW, et al. Randomised controlled trial of dual blockade of renin-angiotensin system in patients with hypertension, microalbuminuria, and noninsulin dependent diabetes: the candesartan and lisinopril microalbuminuria (CALM) study. Br Med J 2000; 21: 1440-4.

41 Mereles D, Ehlken N, Kreuscher S, Ghofrani S, Hoeper MM, et al. Exercise and respiratory training improve exercise capacity and quality of life in patients with severe chronic pulmonary hypertension. Circulation 2006; 114: 1482-9.

42 Frank L. Powell and Nathalie Garcia. Physiological effects of intermittent hypoxia. High Altitude Med Biol 2000; 1: 125-36. doi:10.1089/15270290050074279.

43 Hambrecht R, Fiehn E, Weigl C, Gielen S, Hamann C, Kaiser R, et al. Regular physical exercise corrects endothelial dysfunction and improves exercise capacity in patients with chronic heart failure. Circulation 
1998; 98: 2709-15.

44 Coats AJ, Adamopoulos S, Radaelli A, McCance A, Meyer TE, Bernardi L, et al. Controlled trial of physical training in chronic heart failure: exercise performance, hemodynamics,ventilation and autonomic function. Circulation 1992; 85: 2119-31.

45 Ades PA, Savage PD, Brawner CA, Lyon CE, Ehrman JK, Bunn JY, et al. Aerobic capacity in patients entering cardiac rehabilitation. Circulation 2006; 113: 2706-12.

46 Pina IL, Apstein CS, Balady GJ, Belardinelli R, Chaitman BR, Duscha $\mathrm{BD}$, et al. Exercise and heart failure: a statement from the American
Heart Association Committee on Exercise, Rehabilitation, and Prevention. Circulation 2003; 107: 1210-25.

47 Muller M, Fasching P, Schmid R, Burgdorff T, WaldhausI W, Eichler HG. Inhibition of paracrine angiotensin-converting enzyme in vivo: Effects on interstitial glucose and lactate concentrations in human skeletal muscle. Eur J Clin Investig 1997; 27: 825-30.

48 Frossard M, Joukhadar C, Steffen G, Schmid R, Eichier HG, Müller M. Paracrine effects of angiotensin converting-enzyme and angiotensin II receptro inhibition on transcapillary glucose transport in hummans. Life Sci 2000; 66: 147-54. 